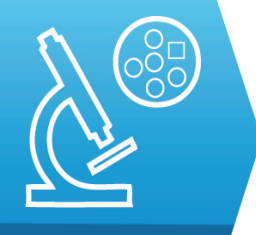

PATHOLOGY
Department of Pathology, Atal Bihari Vajpayee Instititute of Medical Sciences (ABVIMS) \& Dr. Ram Manohar Lohia Hospital, New Delhi, India
DOI: $10.15386 / \mathrm{mpr}-1708$

Manuscript received: 11.05 .2020

Received in revised form: 27.11.2020

Accepted: 17.12.2020

Address for correspondence:

drarvindahuja@gmail.com

This work is licensed under a Creative Commons Attribution-NonCommercialNoDerivatives 4.0 International License

\title{
A clinicopathological study of peripheral schwannomas
}

Ankur Majumder, Arvind Ahuja, DS Chauhan, Purnima Paliwal, Minakshi Bhardwaj

\begin{abstract}
Aim and objective. Schwannomas are benign neoplasms of neural origin with sporadic or syndromic occurence. They are commonly seen in cranial nerves. Peripheral schwannomas occur rarely and may have unique presentations. The aim of this study is to evaluate the clinico-pathological characteristics of peripheral schwannomas.

Methods. A retrospective cross sectional study of peripheral schwannomas excluding head neck region was conducted. The study group consisted of 18 cases which were recorded over a period of seven years. The corresponding data were collected from the archives of the Department of Pathology.

Results. Male to female ratio was 1:1. The average age of the cases was 47 years. The most common site was the upper limbs (55.55\%) followed by lower limbs, chest and penis. The lesions mostly presented as painless swellings (62\%). Histopathological examination revealed classic features of schwannoma. Secondary changes included cystic degeneration, foam cells, epitheloid cells, hyalinization, microcystic change and collection of plasma cells. All cases were confirmed by positive $\mathrm{S} 100$ staining.

Conclusion. Peripheral schwannomas may be missed due to its rarity and atypical presentations. Both clinicians and pathologists should be aware of this common entity at unusual sites for the proper management of the patients. Surgery is usually the treatment of choice.
\end{abstract}

Keywords: peripheral schwannoma, histopathology, secondary changes, upper limb, nerve sheath tumour

\section{Introduction}

Schwannomas are benign encapsulated lesions that have a neuroectodermal origin. The cells of origin are Schwann cells which are responsible for maintaining the myelin sheath of neurons [1]. The common sites for schwannomas are cranial nerves. They have a predilection for sensory nerves, the most commonly affected being the $8^{\text {th }}$ nerve [2]. Among the motor nerves, facial nerve is most frequently affected. Schwannomas account for $8 \%$ of all the primary brain tumors, $80-90 \%$ of which are situated in the cerebellopontine angle [3].
Schwannomas are usually isolated, solitary, slow-growing, and wellencapsulated lesions, except when they are associated with neurofibromatosis. In the latter case, the patients can develop multiple schwannomas, in which case the condition is termed schwannomatosis $[4,5]$.

Peripheral schwannomas on the other hand have a relatively lower incidence of 0.6 per 100,000 people annually, with majority of these cases located on the flexor surfaces of the limbs [1]. They may cause symptoms due to mass effect or erosion of the adjacent bone. Sporadic peripheral schwannomas 
(SPSs) show no significant sex predilection, affect patients across a wide age range and typically present between the $4^{\text {th }}$ and $6^{\text {th }}$ decades of life. Neither the age at presentation nor the clinical course varies significantly between histological subtypes (i.e., cellular, plexiform, or ancient). Peripheral schwannomas are usually associated with loss of heterozygosity of the merlin gene present on chromosome 22 and is usually syndromically associated with neurofibromatosis 2 (NF2) [6,7].

The aim of the present study is to evaluate the clinico-pathological characteristics of peripheral schwannomas, excluding the head and neck region.

\section{Methods}

This is a reterospective cross sectional observational study. Patients records were searched for a period of seven years, between 2013 and 2019, from the archives in the Department of Pathology, ABVIMS and Dr RML Hospital, New Delhi and the slides were reviewed. All patients who were diagnosed with schwannoma by histopathology, excluding the head and neck region, were included irrespective of their clinical diagnosis. The study group consisted of 18 cases.

\section{Results}

The demographic details of all the patients are enlisted in table I.

\section{Age and sex}

Out of 18 cases, nine $(50 \%)$ were males and nine $(50 \%)$ were females, with a sex ratio of $1: 1$. The age of the patients ranged from 16 to 75 years with a mean age of 47 years. Seventeen cases were adult and only one case was an adolescent of 16 years of age with a lesion on the chest wall. Two patients were elderly.

\section{Site}

Among the cases studied, upper limbs were the most common site accounting for 10 cases $(55.55 \%)$, followed by lower limbs (4cases), trunk (3 cases) and penis (1 case).

\section{Clinical presentation and diagnosis}

Most patients came to the outpatient department with a painless nodule. The symptoms ranged from painless swellings to nerve compression symptoms like tingling and burning sensations. Other than schwannoma, various clinical diagnoses like ganglion cyst, lipoma, Dupuytren's contracture, fibroma, hydatid cyst, hemangioma, epidermal inclusion cyst (EIC) and benign mesenchymal cystic lesion were offered. Excision after local or block anesthesia was performed in all patients.

\section{Histopathological analysis}

Grossly, the lesions ranged in size from $1 \mathrm{~cm}$ to $9 \mathrm{~cm}$ in the greatest dimension. The microscopic examination of all of the cases revealed the classic findings of a peripheral nerve sheath tumor. Most of the lesions were encapsulated. However, three cases, one each from the upper limb, lower limb and the chest wall were found to be non-encapsulated. The majority of the lesions were found at a deeper level in the subcutis, with the exception of two cases which were found just beneath the epidermis.

In addition to classical Antoni A, Antoni B areas and Verocay bodies, some unusual histological features were also noted. Epitheloid cell morphology of the tumor cells were seen in three cases. Two cases showed a tumor with distinct clear cell like areas (Figure 1a). Hyaline globules were seen in one case from the lower limbs. Two cases showed ulceration of the overlying epidermis (Figure 1b). Extensive areas of cystic degeneration were noted in two cases (Figure 1c).

Table I. Demographic profile of patients.

\begin{tabular}{l|c|c|c|c} 
S.No & Age & Sex & Clinical diagnosis & Site \\
1 & 29 & F & Hemangioma & Left Hip \\
2 & 34 & F & Soft Tissue swelling & Left cubital region \\
Left hand \\
3 & 30 & F & Lipoma & Left wrist \\
4 & 49 & F & Benign cystic lesion & Left elbow \\
5 & 50 & F & Schwannoma & Thigh \\
6 & 35 & M & Schwannoma & Left ring finger \\
7 & 75 & M & Dupyutren's contracture & Hand \\
8 & 59 & M & Thoracic tumour & Chest Wall \\
9 & 59 & M & Traumatic Granuloma & Left posterior Heel \\
10 & 40 & M & Right Elbow \\
11 & 45 & F & Epidermal inclusion cyst (EIC)/hydatid cyst & Back \\
12 & 26 & F & EIC & Right foot \\
13 & 34 & F & Sebaceous cyst & Back \\
14 & 16 & M & EIC & Left index finger \\
15 & 19 & M & Fibroma & Hand \\
16 & 45 & F & Lipoma & Right ulnar nerve \\
17 & 68 & $\mathrm{M}$ & Penile
\end{tabular}




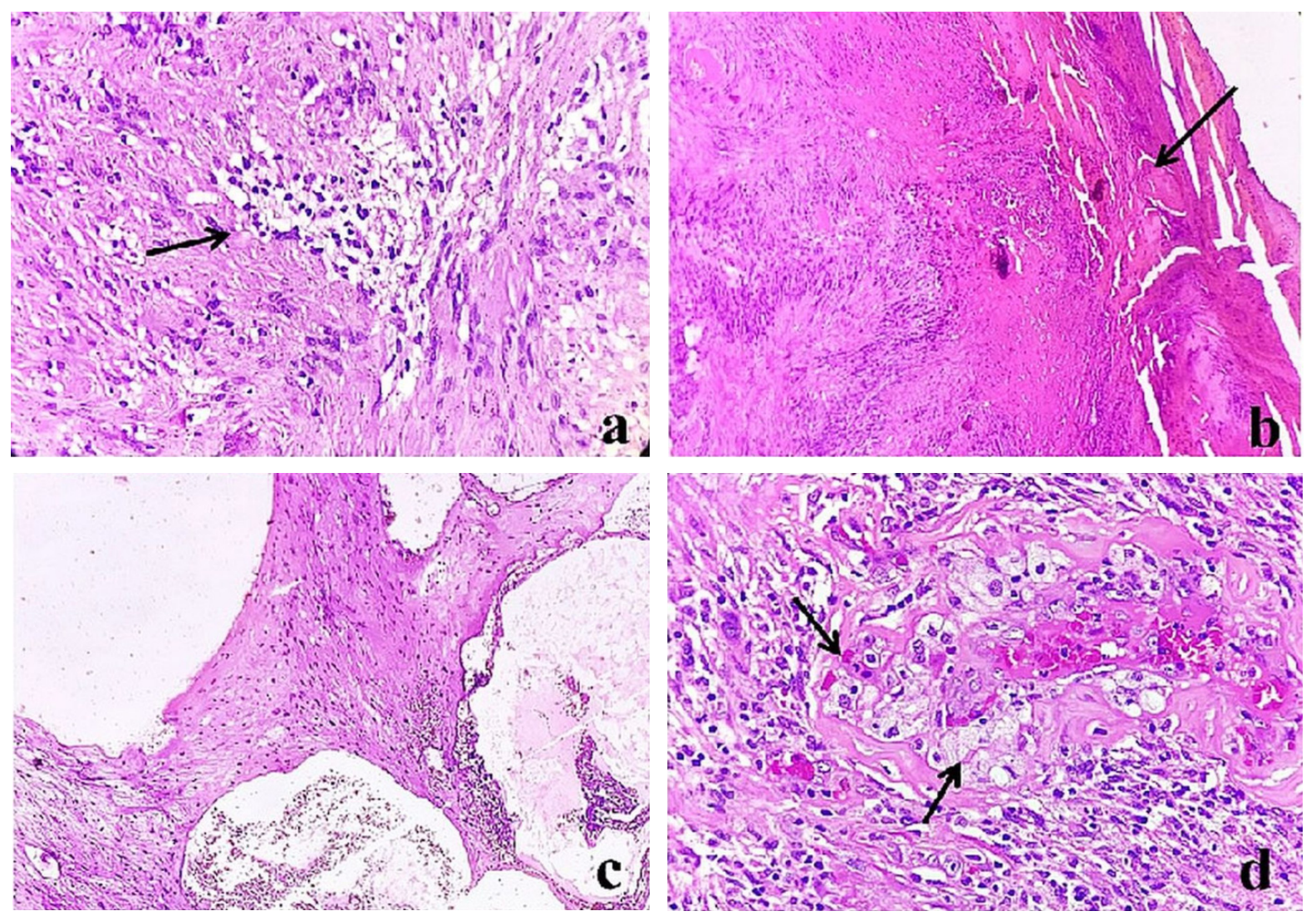

Figure 1. Various histological features of schwannoma. a. Photomicrograph showing clear cell areas (arrow): H\&E (400x); b. Photomicrograph showing an ulceration (arrow) of the epidermis along with underlying schwannoma. Encapsulation is absent: H\&E (100x); c. Photomicrograph showing extensive cystic degeneration. Cysts are lined by flattened cells: H\&E (100x); d. Photomicrograph showing foam cell collection (arrow) within the schwannoma. Surrounding areas show some inflammatory cells: H\&E (400x).

Microcystic degeneration was documented in another two cases. One case from the thigh showed a plexiform morphology. Numerous plasma cells were noted in two cases with long standing history (chest wall and ulnar region of the right elbow). Areas of hyalinization were found in three cases. Collection of foam cells were seen in two cases (Figure 1c). A significant degree of pleomorphism amongst the tumor cells along with occasional mitotic figures were found in only 2 of the 18 cases studied. Both these patients were elderly. All the cases were confirmed by applying S100 immunohistochemistry.

\section{Discussion}

Peripheral nerve schwannomas are a rare entity. However, they can occur at a variety of anatomical locations. The imaging modalities start with ultrasonography which will typically show a solid, sharply delineated, ovoid, hypoechoic homogenous mass [8]. X-rays of the affected area may be done to rule out any bony involvement or abnormalities. Next, MRI with gadolinium contrast can be performed for further evaluation. The classic MRI appearance of schwannomas is iso-intense or show decreased signal intensity relative to skeletal muscle on T1-weighted images and heterogeneously increased signal intensity on T2-weighted images. Some other features of schwannomas are the "fascicular sign", "target sign" and the "split fat sign". However, some of these signs may be seen in neurofibromas too [9].

On microscopy, most schwannomas are tumour masses surrounded by a fibrous capsule consisting of epineurium and residual nerve fibers. The hallmark of a schwannoma is the biphasic pattern of alternating Antoni $\mathrm{A}$ and $\mathrm{B}$ areas. Antoni A areas are composed of compact spindle cells arranged in short bundles or interlacing fascicles showing nuclear palisading, and Verocay bodies, formed by two compact rows of well-aligned nuclei separated by fibrillary cell processes. Antoni B areas are hypocellular areas showing spindle or oval cells arranged haphazardly in a loosely textured matrix. On occasion, schwannomas develop cystic spaces lined by Schwann cells that assume a round or epitheloid appearance [10]. 
Secondary degenerative changes are seen in schwannoma. In a study by Gabhane et al., secondary degenerative changes such as cystic change, hyalinization, necrosis, myxoid change, and verocay bodies were observed in $85.18 \%, 72.22 \%, 59.25 \%, 24.07 \%$, and $70.37 \%$ cases, respectively [11]. In the present study, we have observed cystic change, hyalinization, ulceration, myxoid change and verocay bodies in $16 \%, 16 \%, 11 \%$, $22.22 \%$ and $72.22 \%$ cases. Additional changes that were noted in our study included foam cells, hyaline globules, microcystic degeneration, clear cell areas, epitheloid cells, and collection of plasma cells. However, none of the cases showed necrosis. Few other secondary changes reported in literature include melanotic schwannoma (MS) and psammomatous MS [12].

Histopathological differential diagnoses may include neurofibroma and leiomyoma. Neurofibromas are not encapsulated and lack the biphasic pattern of schwannomas. They have a haphazard arrangement of nerve fibres what is likened to "Shredded Carrot" appearance as opposed to the somewhat oriented nuclei seen in Verocay bodies, a pathognomic feature of schwannomas. Leiomyomas have spindle cells with tapering cytoplasm and elongated blunt ended nuclei as compared to the wavy undulating nuclei seen in cells of neural origin [13].

Immunohistochemically all schwannomas show the presence of S100 protein owing to its neuroectodermal origin. Positivity for Her-2Neu is also noted which shows a characteristic cytoplasmic affinity as compared to its usual membranous staining. Positivity for PDGFR-beta has also been noted in a proportion of cases [6].

\section{Upper limbs}

Benign tumors involving peripheral nerves of the upper extremity are not encountered often. Usually, the ulnar nerve is involved while only $7 \%$ of schwannomas involve the median nerve. In the upper limb, they may be mistaken for ganglion cyst or carpal tunnel syndrome. They usually present as slow growing indolent swellings along the course of the nerve. Multiple lesions may be present in cases of NF type 2 and sporadic schwannomatosis [14]. A study by Adani et al. included 34 cases of upper limb schwannoma. $94 \%$ of these cases presented with a palpable lump, whereas $41 \%$ of these cases presented with a positive Tinel's sign [15]. In a study by Tang et al., 8 cases of upper limb schwannomas were studied. It was found that all of the cases had motor, sensory or mixed nerve deficits [16]. In our study most of the patients with lesions in the upper limbs, especially in the cubital region, had neurological complaints post-surgery. Our study had a total of 10 cases from the upper limb with a mean age of 48 years. Microscopically, secondary changes like epitheloid cells, foam cells and pleomorphism was noted (Table II).
Table II. Comparison of mean age of patients with lesion in the upper limbs.

\begin{tabular}{l|c|c} 
Study name & Number of cases & Mean age (years) \\
\hline Tang et al. & 8 & 56 \\
Adani et al. & 34 & 44 \\
Our study & 10 & 48
\end{tabular}

\section{Lower limbs}

Symptomatic schwannomas are very uncommon in the lower extremity and are particularly rare in the foot and ankle region. The reported cases range from $1 \%$ to $10 \%$ [17]. In a review by Kim et al., out of 397 peripheral nerve sheath tumors only 32 schwannomas $(8.86 \%)$ were located in the lower extremity [18]. Odom et al. reviewed published case reports and estimated that the prevalence of schwannomas occurring in the foot is only $2.93 \%$ [19]. Our study had a total of 4 cases from the lower limb including the hip and the heel, accounting for $22.22 \%$ of cases. The mean age in our study was 34 years. Symptoms due to sustained pressure including ulceration of the overlying skin were noted. These changes were confirmed microscopically. One case showed plexiform morphology (Table III).

Table III. Comparison of mean age of patients with lesion in the lower limbs.

\begin{tabular}{l|c|c|}
\hline Study name & Number of cases & Mean age (years) \\
\hline Kim et al. & 32 & 45 \\
Jha et al. [20] & 1 & 71 \\
Our study & 4 & 34
\end{tabular}

\section{Chest wall and back}

Chest wall schwannomas are rare lesions arising from the intercostal nerves. In a study by Akyildiz et al., the clinical and histopathological features of 42 patients diagnosed with neurogenic tumors of the thorax were studied. Out of these, $20(48 \%)$ were schwannomas with only nine (21\%) localized to the chest wall [21].

Matsumoto et al. reported the case of a 19 -year-old female who was admitted for a $2 \mathrm{~cm}$ lesion on the pleura incidentally found on CT scan. Chest wall ultrasound found the tumor to be arising from intercostal space, which after surgical resection of the intercostal nerve was found to be schwannoma [22]. Schwannomas on the back may also arise from intercostal nerves [23]. In our case we have reported a single case of chest wall schwannoma in a 59-year-old male who presented with a radiating pain towards the scapula. Two patients with lesions on the back (below the ribcage and lower back) were included. Both these lesions were located in the subcutaneous plane and were painful which led to a clinical diagnosis of EIC. Microscopic examination revealed a well encapsulated schwanomma just underlying the epidermis (Table IV). 
Table IV. Comparison of mean age of patients with lesion in chest wall and back.

\begin{tabular}{l|c|c|}
\hline Study name & Number of cases & Mean age (years) \\
\hline Galukande et al. & 1 & 42 \\
Matsumoto et al. & 1 & 19 \\
Our study & 3 & 33
\end{tabular}

\section{Penis}

Schwannomas affecting the penis are exceedingly rare. A review by Nguyen et al. included 33 cases of penile schwannoma. Most of the lesions presented on the dorsal aspect of the penis and the penile body or shaft. Twenty patients presented with single nodule and ten with multiple nodules. The lesions were generally painless; however, sexual dysfunction was a common complaint [24]. There have been only few reported cases of multiple penile schwannomatosis [25]. Our case included a single patient aged 55 years who presented with a painless swelling of insidious onset on the shaft. Microscopically a classical biphasic pattern was noted (Table V).

Table V. Comparison of mean age of patients with lesion on penis.

\begin{tabular}{l|c|c|}
\hline Study name & Number of cases & Mean age (years) \\
\hline Nguyen et al. & 29 & 39 \\
Jiang et al. & 5 & 37 \\
Our study & 1 & 55
\end{tabular}

Malignant transformation of schwannoma is exceedingly rare. The histology of malignant component in most of the lesions was epitheloid morphology [26]. In a study by Kransdorf et al., a large series of 31,047 soft tissue masses were included. The incidence of malignant schwannomas was $6.3 \%$ in this study [27]. In our study, two cases showed pleomorphism and occasional mitotic figures; however malignant transformation was not seen on follow up.

Surgical excision is the treatment of choice. Excisional biopsy can be effectively performed in most cases owing to the lesion's encapsulation and eccentric position within the epineurium [8].

Donner et al. studied a sample of 76 patients with schwannomas who had undergone surgical resection of the tumor. The baseline function was either preserved or improved in $89 \%$ of the patients [28]. However, if a nerve fascicle or fascicles are damaged during surgery, there may be neurological complications including pain and loss of motor or sensory function. The recurrence of schwannoma at the surgical site after excision is generally infrequent [9].

\section{Conclusion}

When encountering a soft tissue mass anywhere in the body, one must consider the possibility of a neurogenic tumor. Schwannomas are benign lesions with very good prognosis and minimal chance of malignant progression. They have a predilection for cranial nerves and spinal nerve roots. However, due to the occasional varied distribution of their location and misleading presentations, it may be confused with mesenchymal lesions. Histopathology of the excised lesions is the gold standard to reach a definitive diagnosis.

Therefore, both clinicians and pathologists should be aware of this common entity at unusual sites for the proper management of the patients.

\section{References}

1. Hanemann CO, Evans DG. News on the genetics, epidemiology, medical care and translational research of Schwannomas. J Neurol. 2006;253:1533-1541.

2. Ward BK, Gourin CG, Francis HW. Vestibular schwannoma surgical volume and short-term outcome in Maryland. Arch Otolaryngol Head Neck Surg.2012;138:577-583.

3. Scott WW, Koral K, Margraf LR, Klesse L, Sacco DJ, Weprin BE. Intracerebral schwannomas: a rare disease with varying natural history. J Neurosurg Pediatr. 2013;12:6-12.

4. Antinhemino J, Sankila R, Carpén O, Pukkala E, Sainio M, Jääskeläinen J. Population-based analysis of sporadic and type 2 neurofibromatosis-associated meningiomas and schwannomas. Neurology. 2000;54:71-76.

5. Jack CM, Jones G, Edwards MR, Singh SK. A case report of three peripheral schwannomas attached to the Achilles paratenon. Foot (Edinb). 2010;20:78-80.

6. Young ED, Ingram D, Metcalf-Doetsch W,Khan D, Al Sannaa G, Le Loarer F, et al. Clinicopathological variables of sporadic schwannomas of peripheral nerve in 291 patients and expression of biologically relevant markers. J Neurosurg. 2018;129:805-814.

7. Lodding P, Kindblom LG, Angervall L, Stenman G. Cellular schwannoma. A clinicopathologic study of 29 cases. Virchows Arch A Pathol Anat Histopathol. 1990;416:237248.

8. Beaman FD, Kransdorf MJ, Menke DM. Schwannoma: radiologic-pathologic correlation. Radiographics. 2004;24:1477-1481.

9. Murphey MD, Smith WS, Smith SE, Kransdorf MJ, Temple HT. From the archives of the AFIP.Imaging of musculoskeletal neurogenic tumors: radiologic-pathologic correlation. Radiographics. 1999;19:1253-1280.

10. Padasali PS, Shankaregowda VS, Kshirsagar SD. Median nerve schwannoma: A case and review of literature. Asian J Neurosurg. 2015;10:212-215.

11. Gabhane SK, Kotwal MN, Bobhate SK. Morphological spectrum of peripheral nerve sheath tumors: a series of 126 cases. Indian J Pathol Microbiol. 2009;52:29-33.

12. Chikkannaiah P,Boovalli MM,Nathiyal V,Venkataramappa S. Morphological spectrum of peripheral nerve sheath tumors: An insight into World HealthOrganization 2013 classification. J Neurosci Rural Pract. 2016;7:346-354.

13. Sawas FA, Lababede O, Meziane MA, Arrossi AV. A 54-year-old woman with incidentally discovered mass on a 
chest radiograph. Chest. 2009;135:1673-1678.

14. Park MJ, Seo KN, Kang HJ.Neurological deficit after surgical enucleation of schwannomas of the upper limb. J Bone Joint Surg Br. 2009;91:1482-1486.

15. Adani R, Baccarani A, Guidi E, Tarallo L. Schwannomas of the upper extremity: diagnosis and treatment. Chir Organi Mov. 2008;92:85-88.

16. Tang CY, Fung B, Fok M, Zhu J. Schwannoma in the upper limbs. Biomed Res Int. 2013;2013:167196.

17. Mott RC, Dellon AL. Multiple schwannomas of the foot: case report and strategy for treatment. J Am Podiatr Med Assoc. 2003;93:51-57.

18. Kim DH, Murovich JA, Tiel RL, Moes G, Kline DG. A series of 397 peripheral neural sheath tumors: 30-year experience at Louisiana State University Health Sciences Center. J Neurosurg. 2005;102:246-255.

19. Odom RD, Overbeek TD, Murdoch DP, Hosch JC. Neurilemoma of the medial plantar nerve: a case report and literature review. J Foot Ankle Surg. 2001;40:105-109.

20. Jha AJ, Basetty CR, Viner GC, Tedder C, Shah A. Posterior Tibial Nerve Schwannoma Presenting as Tarsal Tunnel Syndrome. Cureus. 2019;11:e5303.

21. Akyildz EU, Yalcinkaya U. Thoracic neurogenic tumors: a clinicopathologic evaluation of 42 cases. Neurol Asia. 2015;1:59-63.

22. Matsumoto T, Kanzaki M, Wachi N, Onuki T. Surgically treated chest wall schwannoma without entering the pleural space utilizing ultrasonography. Kyobu Geka. 2009;62:557559.

23. Galukande M, Khingi A. Chest wall schwannoma presenting as a solitary malignant lesion: a case report.Springerplus. 2016;5:1549.

24. Nguyen AH, Smith ML, Maranda EL, Punnen S. Clinical Features and Treatment of Penile Schwannoma: A Systematic Review. Clin Genitourin Cancer. 2016;14:198-202.

25. Jiang R, Chen JH, Chen M, Li QM. Male genital schwannoma, review of 5 cases. Asian J Androl. 2003;5:251-254.

26. Woodruff JM, Selig AM, Crowley K, Allen PW. Schwannoma (neurilemoma) with malignant transformation. A rare, distinctive peripheral nerve tumor. Am J Surg Pathol. 1994; 18:882-895.

27. Kransdorf MJ. Malignant soft-tissue tumors in a large referral population: distributionof diagnoses by age, sex, and location. AJR Am J Roentgenol. 1995;164:129-134.

28. Donner TR, Voorhies RM, Kline DG. Neural sheath tumors of major nerves. J Neurosurg. 1994;81:362-373. 